Обоснование. Учитывая, что беременность рассматривается в качестве естественной модели метаболического синдрома (MC), а также важное значение метаболических нарушений в развитии эссенциальной гипертензии, актуализировано углубленное исследование дисметаболических механизмов в генезе преэклампсии (ПЭ).

Цель. Для оценки роли метаболических нарушений в развитии ПЭ выявить клинико-лабораторные параллели при беременности, осложненной ПЭ без сопутствующей соматической патологии, и беременности, протекающей на фоне МС. Memoды. В динамике беременности обследованы 82 женщины с МС, которые по факту реализации пЭ были разделены на 2 группы: I группу составили 50 женщин с ПЭ на фоне МС, II группу 32 женщины с МС без ПЭ. Для оценки патогенетического значения метаболических нарушений в развитии ПЭ была сформирована III группа, состоящая из 44 беременных с ПЭ без сопутствующей соматической патологии. IV (контрольную) группу составили 30 здоровых женщин с физиологической беременностью. У всех беременных определялись метаболические, гематологические показатели, гормоны, маркеры провоспалительного состояния, эндотелиально-гемостазиологической дисфункции, децидуализации и плацентарного ангиогенеза, динамика накопления и локусы распределения жировой ткани.

Результаты. В группах беременных с ПЭ выявлены схожие с МС изменения: выраженные диабетогенные и атерогенные нарушения с развитием патологических инсулинорезистентности, гиперинсулинемии и лептинемии, гиперактивация эндотелиально-тромбоцитарного звена, тромботический и воспалительный статус, висцеральный тип жироотложения, гиперурикемия, гиперсимпатикотония. Доказано, что в иерархии механизмов формирования ПЭ плацентарная дисфункция выступает второстепенным фактором альтерации, дополнительно потенцирующим нарастание инсулинорезистентности и эффекты структурно-функциональной дестабилизации сосудистого эндотелия. Заключение. Направленность метаболических изменений при беременности, общность развития ПЭ и МС свидетельствуют о важной роли дисметаболических механизмов в формировании ПЭ.

КЛЮЧЕВЫЕ СЛОВА: преэклампсия; метаболический синдром; дисметаболические механизмы патогенеза; инсулинорезистентность; гиперинсулинемия; дислипидемия.

\title{
DYSMETABOLIC MECHANISMS OF PREECLAMPSIA DEVELOPMENT
}

\author{
(c) Igor S. Lipatov*, Yuri V. Tezikov, Amir R. Azamatov
}

Samara State Medical University, Samara, Russia

BACKGROUND: An in-depth study of dismetabolic mechanisms in the genesis of pre-eclampsia (PE) has been updated because pregnancy is considered as a natural model of metabolic syndrome (MS), as well as the metabolic disorders are important in development of essential hypertension.

AIMS: to reveal clinical and laboratory parallels in pregnancy complicated by PE without MS and pregnancy proceeding on the background of MS to assess the role of metabolic disturbances in the development of PE.

MATERIALS AND METHODS: 82 women with MS were examined in the dynamics of pregnancy and were divided into 2 groups depending on the implementation of PE: group I consisted of 50 women with PE on the background of MS, group II 32 women with MS without PE. We formed group III consisting of 44 pregnant women with PE without accompanying diseases to assess the pathogenetic value of metabolic disorders in the development of PE. The IV (control) group consisted of 30 healthy women with physiological pregnancy. Metabolic, hematological parameters, hormones, markers of the proinflammatory state, endothelial hemostasiological dysfunction, decidualization and placental angiogenesis, accumulation dynamics and distribution loci of adipose tissue were determined in all pregnant women.

RESULTS: In the groups of pregnant women with PE, changes similar to MS were revealed: pronounced diabetic and atherogenic disorders with the development of pathological insulin resistance, hyperinsulinemia and leptinemia, endothelial-platelet link hyperactivation, thrombotic and inflammatory status, visceral type of fat deposition, hyperuricemia, hypersympathicotonia. It is proved that in the hierarchy of mechanisms of PE formation, placental dysfunction is a secondary alteration factor, which additionally potentiates the insulin resistance increase and the effects of structural and functional destabilization of the vascular endothelium.

CONCLUSIONS: The direction of metabolic changes during pregnancy, the common development of PE and MS indicate the important role of dismetabolic mechanisms in the formation of PE.

KEYWORDS: pre-eclampsia; metabolic syndrome; pathogenesis; insulin resistance; hyperinsulinemia; dyslipidemia. 


\section{ОБОСНОВАНИЕ}

По данным ВО3, в 2018 г. 2 млрд населения планеты имели избыточную массу тела [1]. Проводимые метаанализы показывают, что метаболический синдром (MC) имеет место у каждого 3-4-го в популяции взрослого населения. За ближайшие 25 лет ожидается увеличение темпов его роста на 50\%, что обусловлено изменениями образа жизни и технологий производства продуктов питания [1, 2]. В связи с этим становится понятной столь масштабная распространенность во всем мире артериальной гипертензии (АГ), одним из важнейших звеньев которой являются метаболические нарушения. Среди причин эссенциальной АГ у взрослых более $80 \%$ занимает MC $[2,3]$. Характерные для MC инсулинорезистентность (ИР) и гиперинсулинемия (ГИ) способствуют повышению реабсорбции $\mathrm{Na}+$ и воды в почках, активации ренин-ангиотензин-альдостероновой и симпатической нервной систем, гипертрофии и ремоделированию стенок сосудов и сердца - важнейшим патогенетическим звеньям АГ. К факторам кардиоваскулярного риска относятся многие признаки МС: изменения уровней общего холестерина (OX), липопротеидов низкой/высокой плотности (ЛПВП/ЛПНП), мочевой кислоты, протромбогенное состояние, сахарный диабет, избыточный вес или ожирение $[4,5]$.

С точки зрения общесоматических подходов, преэклампсия (ПЭ) является вариантом осложненного гипертонического криза [6]. При этом МС выступает независимым фактором риска как эссенциальной АГ, так и ПЭ, частота реализации которой при наличии МС достигает 80\% [4, 7]. Необходимо отметить, что жизнеобеспечение плода, являющееся главенствующей функцией беременности, осуществляется за счет эволюционно закрепленных и в определенной степени неблагоприятных для организма будущей матери изменений, схожих с МС (формирование «диабетогенного» состояния, проявляющегося ИР и ГИ в ответ на выработку плацентарных контринсулярных гормонов, атерогенный сдвиг липидного спектра, эндотелиально-тромбоцитарная активация, провоспалительные и гиперкоагуляционные изменения, гиперурикемия, симпатикотония) $[8,9]$. Это позволяет рассматривать физиологическую беременность как естественную модель МС. Однако характерный для «нормы беременности» баланс факторов «физиологического повреждения» и механизмов перманентной гестационной адаптации обеспечивает благоприятный исход как для плода, так и для беременной [10]. Учитывая, что ПЭ является болезнью дезадаптации, вышеуказанная направленность метаболических процессов при патологическом нарастании изменений может активно участвовать в патогенезе данного тяжелого осложнения гестации.

\section{ЦЕЛЬ}

Для оценки роли метаболических нарушений в развитии ПЭ выявить клинико-лабораторные параллели при беременности, осложненной ПЭ без сопутствующей соматической патологии, и беременности, протекающей на фоне MC.

\section{МЕТОДЫ}

Дизайн исследования

Одноцентровое проспективное наблюдательное клиническое исследование.

\section{Критерии соответствия}

Критериями отбора женщин с МС выступали: выявляемые до гестации критерии МС (1 обязательный признак - абдоминальное ожирение (окружность талии $>80$ см) и 2 дополнительных: содержание триглицеридов (ТГ) в сыворотке крови >1,7 ммоль/л, уровень ЛПВП в сыворотке крови <1,29 ммоль/л, АД $\geq 130 / \geq 85$ мм рт.ст.), возраст женщин до 35 лет, сохраненные менструальный и овуляторный яичниковый циклы. С целью ограничения влияния изначально существующей гипергликемии на процессы гестационной метаболической перестройки все женщины с МС имели догестационный уровень глюкозы венозной крови <6,1 ммоль/л. Критерии включения в III группу: догестационные индекс массы тела (ИМТ) 18,5-24,9 кг/м², уровень АД <130/<85 мм рт.ст., отсутствие метаболических нарушений, возраст женщин до 35 лет. Критериями исключения из исследования являлись: догестационные нарушения углеводного обмена, гестационный сахарный диабет, тяжелая соматическая, инфекционно-воспалительная, генетическая, психическая патология (кроме MC в I и II группах), синдром поликистозных яичников, аномалии половых органов, беременность после вспомогательных репродуктивных технологий, врожденная патология плода. Все участницы получили исчерпывающие ответы на интересующие вопросы и подписали информированное добровольное согласие на участие в исследовании.

\section{Условия проведения}

Исследование проведено на базе Перинатального центра ГБУЗ «СОКБ им В.Д. Середавина» г.о. Самара.

\section{Продолжительность исследования}

Исследование проведено в 2015-2019 гг. Клинико-лабораторное обследование беременных I, II, IV групп выполнялось в динамике в 11-14 и 30-34 нед, беременные с ПЭ III группы обследовались в 30-34 нед.

\section{Описание медицинского вмешательства}

У всех женщин выполнялся забор венозной крови утром натощак с целью определения метаболических (глюкоза венозной крови, ОХ, ЛПВП, ТГ в сыворотке крови с вычислением коэффициента атерогенности (КА) и отношения ТГ/ЛПВП, индекса инсулинорезистентности (HOMA-IR), мочевая кислота) и гематологических (количество, агрегация (с коллагеном), средний объем и фракция незрелых тромбоцитов, количество лейкоцитов, нейтрофилов) показателей, уровней гормонов (инсулина, лептина, плацентарного лактогена (ПЛ)), провоспалительных маркеров (фактора некроза опухоли альфа (ФНО-а), С-реактивного белка (СРБ)), индекса активации лейкоцитов, показателей состояния эндотелия сосудов (циркулирующих эндотелиальных клеток (ЦЭК), метаболитов оксида азота (II), фибронектина (ФН)), плацентарного альфа-1-микроглобулина (ПАМГ-1) и фактора роста плаценты (ФРП). Методом УзИ определяли 
динамику накопления и локусы распределения жировой ткани: толщину подкожного (тПКЖ) и преперитонеального (тППЖ) жира с расчетом индекса жира брюшной стенки (ИЖБС=тППЖ/тПКЖ). В условиях акушерского стационара оценены тип суточной вариабельности АД, эпизоды ночного апноэ. Субъективная оценка характеристики сна осуществлялась путем заполнения анкеты Я.И. Левина (1995).

\section{Основной исход исследования}

Получение данных метаболических, гематологических показателей, гормонов, маркеров провоспалительного состояния, эндотелиально-гемостазиологической дисфункции, децидуализации, данных о динамике накопления и локусах распределения жировой ткани, типах суточной вариабельности АД, эпизодах гестационного сонного апноэ и о признаках инсомнии с целью оценки их роли в патогенезе ПЭ.

\section{Дополнительные исходы исследования}

Получение данных о содержании ФРП и особенностях клинической реализации плацентарной недостаточности (ПН) в группах сравнения с целью оценки роли ПН в развитии ПЭ.

\section{Анализ в подгруппах}

В динамике беременности проведено углубленное клинико-лабораторное обследование 82 женщин с MC, которые по факту реализации ПЭ были разделены на 2 группы: I группу составили 50 беременных с MC, у которых развилась ПЭ; во II вошли 32 беременные с МС без ПЭ. В I группе ПЭ диагностирована в сроки 28-35 нед беременности. Для оценки патогенетического значения метаболических нарушений в развитии ПЭ была сформирована III группа из 44 женщин с ПЭ без сопутствующей соматической патологии, имеющих аналогичные I группе сроки манифестации и степень тяжести ПЭ. IV (контрольную) группу составили 30 здоровых женщин с физиологической гестацией.

\section{Методы регистрации исходов}

Уровень глюкозы в плазме венозной крови определялся гексокиназным методом, значение ОХ, ТГ, ЛПВП, метаболитов NO (II) - колориметрическим методом. Коэффициент атерогенности рассчитывался по формуле A.H. Климова (1984). HOMA-IR (D. Matthews (1985)) pacсчитывался по следующей формуле: HOMA-IR = уровень глюкозы крови натощак (ммоль/л) $\times$ уровень инсулина крови натощак (пмоль/л) ×0,138/ 22,5.

Концентрации инсулина, лептина, ПЛ, ФНО-а, СРБ, ФРП, ПАМГ-1 в сыворотке крови, ФН в плазме крови определялись методом ELISA. Подсчет количества ЦЭК в крови осуществлялся методом Н.Н. Петрищева (2001). Индекс активации лейкоцитов рассчитывался способом, предложенным Н.Ю. Сотниковой (1998) [9]. Диагностика и оценка степени тяжести ПЭ проводились в соответствии с рекомендациями ВО3 [11]. Диагностика степени тяжести ПН осуществлялась по критериям А.Н. Стрижакова и соавт. (2014) [12]. В исследовании использованы биохимический анализатор Architect c4000 (Abbott, США), гематологический анализатор Sysmex XN-1000 (Sysmex Corporation, Япония), лазерный анализатор агрегации тромбоцитов АЛАТ-2 ООО НПФ «Биола», ультразвуковая система экспертного класса Voluson E6 GE Healthcare (Австрия).

\section{Этическая экспертиза}

Проведение исследования одобрено Комитетом по биоэтике и Научно-образовательным центром доказательной медицины при ФГБОУ ВО «СамГМУ» Минздрава России (протокол № 158 от 19.02.2015).

\section{Статистический анализ}

Расчет размера выборки. Размер выборки рассчитывали по номограмме Альтмана с учетом данных предварительного исследования: при мощности исследования 80\% достаточная численность групп будет от 30 наблюдений.

Статистический анализ. Статистическая обработка числового массива данных выполнена при помощи специализированного программного обеспечения IBM SPSS Statistics 25 HC IMAGO 5.0, лицензия №5725-A54. Нормальность распределений значений оценивалась по критериям Колмогорова-Смирнова с поправкой Лиллиефорса и Шапиро-Уилка. Для показателей с нормальным распределением вычислялись среднее арифметическое (M) и стандартное отклонение (SD), статистическая значимость межгрупповых различий определялась по критерию Тьюки. При непараметрическом распределении вычислялась медиана (Ме) с межквартильным интервалом $\left[Q_{1}(25 \%) ; Q_{3}(75 \%)\right]$, рассчитывался критерий U Манна-Уитни с поправкой Бонферрони. При сравнении зависимых выборок (динамика показателей в течение беременности) использовался парный критерий Вилкоксона. Для выявления взаимосвязей применяли корреляционный анализ Спирмена. Критическое значение уровня статистической значимости принимали менее 0,05.

\section{РЕЗУЛЬТАТЫ}

Объекты (участники) исследования

Средняя масса тела до беременности в I и II группах составила 93 (6) кг и 92 (7) кг соответственно (p=0,84). ИМТ

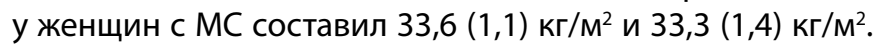
В I группе ИМТ 30-35 кг/м² имел место у 88\% (44/50) женщин, а ИМТ 35-40 кг/м² - у 12\% (6/50); во II группе ИМТ 30-35 кг/м² имел место у 90,6\% (29/32) женщин, а ИМТ 35-40 кг/м² - у 9,4\% (3/32). Межгрупповые статистические различия по ИМТ отсутствуют $\left(x^{2}=0,14 ; p=0,71\right)$. Среднее значение окружности талии - 104 (6) см и 102 (5) см соответственно в I и II группах (p=0,71). У 46\% (23/50) женщин I группы и 43,8\% (14/32) женщин II группы была контролируемая АГ. Средний уровень АДс составил 128 (6) мм рт.ст. в I группе и 127 (5) мм рт.ст. во II группе $(p=0,85)$; средний уровень АДд составил 78 (5) мм рт.ст. в I группе и 76 (6) мм рт.ст. во II группе $(p=0,83)$. У женщин с MC до беременности наблюдались атерогенные изменения липидного спектра: средние значения ОХ равнялись 6,23 ммоль/л [5,37; 6,83] и 6,12 ммоль/л [5,24; 6,71] $(p=0,82)$, ТГ - 1,86 ммоль/л $[1,76 ; 2,35]$ и 1,84 ммоль/л $[1,77 ; 2,31](p=0,89)$, лПВП - 1,05 ммоль/л $[0,97 ; 1,16]$ и 1,03 ммоль/л $[0,98 ; 1,12] \quad(p=0,79)$, соотношения ТГ/ХС ЛПВП - 1,63 [1,34; 2,61] и 1,61 $(1,37 ; 2,55](p=0,81)$, КА - 5,3 $[4,9 ; 5,8]$ и 5,1 $[4,7-5,5](p=0,63)$ соответственно в I и II группах. Следовательно, основу I и II групп сравне- 
ния составили пациентки с абдоминальным ожирением, нарушенным липидным спектром и контролируемой АГ.

Среди женщин III группы из независимых факторов высокого риска ПЭ в 63,6\% (28/44) наблюдений выявлен отягощенный ПЭ акушерский анамнез, в 36,4\% (16/44) отягощенный семейный анамнез с наличием ПЭ у матери или родных сестер. Анализ медицинской документации подтвердил отсутствие догестационного нарушения лабораторных показателей углеводного и липидного обменов, а также повышения АД в указанной группе.

\section{Основные результаты исследования}

Анализ медико-социального статуса женщин сравниваемых групп не показал статистически значимых различий по возрасту, профессиональной принадлежности, семейному положению, району проживания, бытовым условиям ( $>>0,05)$. Перво- и повторнобеременные в группах составили: первобеременные 34 (17/50), 31,2 (10/32), 29,5 (13/44), 33,3\% (10/30); повторнобеременные - 66 (33/50), 68,8 (22/32), 70,5 (31/44), $66,7 \%$ (20/30) соответственно I, II, III, IV группам $\left(X^{2}=0,25\right.$; $\mathrm{p}=0,97)$.

Частота реализации ПЭ среди женщин с МС составила 61\% (50/82), при этом умеренная ПЭ диагностирована в $60 \%(30 / 50)$ и 56,8\% (25/44) $\left(x^{2}=0,01 ; p=0,92\right)$, тяжелая ПЭ - в 40\% (20/50) и 43,2\% (19/44) $\left(x^{2}=0,01, p=0,92\right)$ наблюдений I и III групп соответственно, что объективизирует их сопоставимость по степени тяжести ПЭ. Среди прочих осложнений гестации у женщин I, II, III групп встречались: среднетяжелый токсикоз - в 20,0, 18,8 и $6,8 \% \quad\left(x_{1-3}^{2}=2,39, p_{1-3}=0,12 ; \quad X_{2-3}^{2}=0,01, p_{2-3}=0,92 ;\right.$ $\left.\mathrm{X}_{1-2}^{2}=0,02, \mathrm{p}_{1-2}=0,88\right)$, угроза прерывания беременности - в 54,0, 43,8 и 31,8\% ( $\mathrm{X}_{1-3}=4,68, \mathrm{p}_{1-3}=0,03 ; \mathrm{X}_{2-3}^{2}=0,68$, $\left.\mathrm{p}_{2-3}=0,41 ; \mathrm{x}_{1-2}^{2}=0,46, \mathrm{p}_{1-2}=0,50\right)$, угроза преждевременных родов - в 34,0, 9,4 и 29,5\% ( $\mathrm{X}_{1-3}=0,06, \mathrm{p}_{1-3}=0,81 ; \mathrm{x}_{2-3}=3,40$, $\left.\mathrm{p}_{2-3}=0,07 ; \mathrm{x}_{1-2}^{2}=5,15, \mathrm{p}_{1-2}=0,02\right)$, патология околоплодных вод - в 28,0, 21,9 и 22,7\% ( $x_{1-3}^{2}=0,12, p_{1-3}=0,73 ; X_{2-3}^{2}=0,04$, $\left.\mathrm{p}_{2-3}=0,85 ; \mathrm{x}_{1-2}^{2}=0,13, \mathrm{p}_{1-2}=0,72\right)$ наблюдений соответственно. В I и III группах встречались преждевременная отслойка нормально расположенной плаценты - в 8,0 и 6,8\% $\left(x^{2}=0,03 ; p=0,86\right)$, HELLP-синдром - в 4,0 и 2,3\% ( $x^{2}=0,01$; $\mathrm{p}=0,91)$ случаев соответственно. Индуцированные и самопроизвольные преждевременные роды преобладали в I (70\% - 35/50) и III (68,2\% - 30/44) группах по сравнению со II $(9,4 \%-3 / 32)-x_{1-2}^{2}=26,5, p_{1-2}<0,001$ и $x_{2-3}^{2}=23,7$, $\mathrm{p}_{2-3}<0,001$.

Проведенный анализ типов суточной вариабельности АД показал, что все беременные группы контроля имели нормальный тип вариабельности - dipper (снижение АД ночью на 10-20\%) [13]. У женщин I, II и III групп встречались патологические типы суточной вариабельности АД: non-dipper (снижение АД ночью на 0-10\%) В 38,0 (19/50), 21,9 (7/32) и 31,8\% (14/44) наблюдений соответственно $\left(X_{1-3}^{2}=0,39, p_{1-3}=0,53 ; X_{2-3}^{2}=0,91, p_{2-3}=0,34\right.$; $\mathrm{X}_{1-2}=2,34, \mathrm{p}_{1-2}=0,13$ ), тип вариабельности night-picker (повышение АД ночью) более чем в 3 раза чаще отмечался в I $(22,0 \%-11 / 50)$ и III $(18,2 \%-8 / 44)$ группах в отличие от женщин с МС без ПЭ $(6,3 \%-2 / 32): x_{1-3}^{2}=0,21, p_{1-3}=0,64$; $\mathrm{X}_{2-3}^{2}=2,31, \mathrm{p}_{2-3}=0,13 ; \mathrm{X}_{1-2}^{2}=2,54, \mathrm{p}_{1-2}=0,11$. Нами получены данные, показывающие, что частота наличия гестационного сонного апноэ составила: в I группе - 66,0 (33/50), во II - 37,5 (12/32), в III - 52,3\% (23/44) наблюдений, при этом в I группе статистически значимо чаще, чем во II $\left(x_{1-2}^{2}=5,30, p_{1-2}=0,01 ; x_{1-3}^{2}=1,31, p_{1-3}=0,25 ; x_{2-3}^{2}=1,08\right.$, $\left.\mathrm{p}_{2-3}=0,28\right)$. По результатам субъективной оценки характеристик сна отмечено наличие инсомнии ( $\leq 18$ баллов; низкое качество сна, частые пробуждения, долгое засыпание, негативные сновидения, сонливость днем) у женщин I, II и III групп в 46,0 (23/50), 15,6 (5/32) и 43,2\% (19/44) наблюдений соответственно $\left(\chi_{1-3}^{2}=0,08, \mathrm{p}_{1-3}=0,78\right.$; $\left.\mathrm{X}_{2-3}^{2}=6,51, \mathrm{p}_{2-3}=0,01 ; \mathrm{X}_{1-2}^{2}=8,01, \mathrm{p}_{1-2}=0,01\right)$. У беременных контрольной группы гестационное сонное апноэ отсутствовало, при субъективной оценке характеристик сна все женщины набрали >22 баллов, что является нормой.

Оценка динамики накопления и локусов распределения жировой ткани у беременных групп сравнения показала, что тППЖ, изначально не различающаяся в 11-14 нед гестации в группах с МС (для I группы - 24,4 (17,1;28,7) мм, для II группы - 23,0 (17,5;28,0) мм; p=0,68), к концу беременности статистически значимо увеличилась в 1,3 раза в I группе с реализовавшейся ПЭ (32,6 (28,4;34,5) мм), при этом различия со II группой $(25,3(21,3 ; 29,2)$ мм) имели достоверный характер $(p=0,01)$. тППЖ также был значительно выражен у женщин III группы $(23,5$ (20,3;27,8) мм), превышая значения контрольной группы $(11,2$ (8,8;14,6) мм) более чем в 2 раза ( $<<0,001)$. ИЖБС имел схожие тенденции в I $(1,4(1,3 ; 1,6))$ и III $(1,6(1,5 ; 1,7))$ группах с достоверным превышением значений по сравнению со II группой $(1,0(0,9 ; 1,1))-p_{1-2}$ и $p_{2-3}<0,001$.

Согласно данным таблиц 1 и 2, уровни инсулина и HOMA-IR в I и II группах с MC соответственно в 1,8 и 1,9 раза превышали показатели контрольной группы в 11-14 нед ( $\left.p_{n 1-4^{\prime}} p_{\text {и2-4 }}<0,001 ; p_{\text {IR1-4, }} p_{\text {IR2-4 }}<0,001\right)$, при этом динамика обоих показателей отражает более выраженное нарастание значений в случае реализации ПЭ (в III триместре $\mathrm{p}_{\text {и1-2, }}, \mathrm{p}_{\mathrm{IR1-2}}<0,001$ ). Полученные данные в III группе по уровням инсулина и HOMA-IR статистически значимо выше, чем у женщин с МС без ПЭ ( $p_{n}<0,001$, $\mathrm{p}_{\mathbb{R}}<0,001$; табл. 2). Уровень глюкозы во всех группах соответствовал норме, что определяется критериями включения и исключения.

Анализ динамики показателей липидного спектра выявил формирование статистических различий по уровням OX, ТГ, ЛПВП, КА, ТГ/ЛПВП между I и II группами в III триместре гестации в сторону нарастания изменений при развитии ПЭ ( $\mathrm{p}_{\mathrm{OX}}=0,01, \mathrm{p}_{\mathrm{Tr}}=0,03, \mathrm{p}_{\text {лпвп, }} \mathrm{p}_{\text {КА }}, \mathrm{p}_{\text {тг/лпвп }}<0,001 ;$ табл. 1 , 2). В III группе полученные значения липидного профиля статистически не различались по сравнению со II группой с МС без ПЭ ( $\mathrm{p}_{\mathrm{Ox}}=0,75, \mathrm{p}_{\mathrm{T \Gamma}}=0,82, \mathrm{p}_{\text {лпвп }}=0,87, \mathrm{p}_{\mathrm{KA}}=0,83$, $\left.\mathrm{p}_{\text {тг/лпвп }}=0,81\right)$. Уровень лептина в I и II группах достоверно' не отличался в 11-14 нед $(\mathrm{p}=0,78)$, однако статистически превышал значения здоровых беременных $\left(\mathrm{p}_{1-4^{\prime}}, \mathrm{p}_{2-}\right.$ $\left.{ }_{4}<0,001\right)$. В III триместре гестации более высокая лептинемия сопутствовала развитию ПЭ как на фоне МС, так и без сопутствующей соматической патологии $\left(\mathrm{p}_{1-2^{\prime}} \mathrm{p}_{2-3}<0,001\right)$.

Показано, что уже с конца I триместра отмечается значительное превышение ПЛ у беременных с ПЭ на фоне $\mathrm{MC}\left(\mathrm{p}_{1-2^{\prime}} \mathrm{p}_{1-4}<0,001\right)$. В 30-34 нед гестации данная закономерность сохранилась, при этом у женщин с ПЭ III группы выявлена аналогичная тенденция. Схожие изменения отмечены при оценке уровня ПАМГ-1 (табл. 1, 2).

Анализ содержания ФНО-а, ведущего провоспалительного цитокина, показал наличие статистических различий между группами уже в 11-14 нед гестации 
Таблица 1. Результаты лабораторного тестирования женщин I, II, IV групп сравнения в 11-14 нед гестации (Me $\left.\left[Q_{1} ; Q_{3}\right]\right)$

\begin{tabular}{|c|c|c|c|}
\hline Лабораторные показатели & $\begin{array}{c}\text { I rpynna } \\
(n=50)\end{array}$ & $\begin{array}{c}\text { II rpynna } \\
(n=32)\end{array}$ & $\begin{array}{c}\text { IV группа } \\
(n=30)\end{array}$ \\
\hline Глюкоза, ммоль/л & $\begin{array}{c}4,6 \\
{[4,1 ; 4,9]}\end{array}$ & $\begin{array}{c}4,5 \\
{[4,1 ; 4,9]}\end{array}$ & $\begin{array}{c}4,5 \\
{[4,1 ; 4,8]}\end{array}$ \\
\hline Инсулин, пмоль/мл & $\begin{array}{c}95,3^{\mathrm{xx}} \\
{[87,7 ; 105,6]}\end{array}$ & $\begin{array}{c}92,1^{\mathrm{xx}} \\
{[83,1 ; 101,7]}\end{array}$ & $\begin{array}{c}52,6 \\
{[40,7 ; 58,1]} \\
\end{array}$ \\
\hline HOMA-IR & $\begin{array}{c}2,70^{\mathrm{xx}} \\
{[2,32 ; 3,18]}\end{array}$ & $\begin{array}{c}2,61^{x x} \\
{[2,36 ; 3,02]}\end{array}$ & $\begin{array}{c}1,40 \\
{[1,12 ; 1,58]}\end{array}$ \\
\hline ОХ, ммоль/л & $\begin{array}{c}6,62^{\mathrm{xx}} \\
{[6,39 ; 6,85]}\end{array}$ & $\begin{array}{c}6,47^{x x} \\
{[5,92 ; 6,69]}\end{array}$ & $\begin{array}{c}4,99 \\
{[4,58 ; 5,28]}\end{array}$ \\
\hline ТГ, ммоль/л & $\begin{array}{c}2,31^{\mathrm{xx}} \\
{[2,22 ; 2,44]}\end{array}$ & $\begin{array}{c}2,21^{x x} \\
{[2,13 ; 2,37]}\end{array}$ & $\begin{array}{c}1,69 \\
{[1,45 ; 1,82]}\end{array}$ \\
\hline ЛПВП, ммоль/л & $\begin{array}{c}0,96^{\mathrm{xx}} \\
{[0,91 ; 1,01]}\end{array}$ & $\begin{array}{c}1,06^{x x} \\
{[0,98 ; 1,12]}\end{array}$ & $\begin{array}{c}1,35 \\
{[1,29 ; 1,40]}\end{array}$ \\
\hline ТГ/ЛПВП & $\begin{array}{c}2,39^{\mathrm{xx}, y} \\
{[2,17 ; 2,65]}\end{array}$ & $\begin{array}{c}2,08^{x x} \\
{[1,88 ; 2,32]}\end{array}$ & $\begin{array}{c}1,25 \\
{[1,06 ; 1,41]}\end{array}$ \\
\hline KA & $\begin{array}{c}5,9^{x x, y} \\
{[5,3 ; 6,4]}\end{array}$ & $\begin{array}{c}5,1^{\mathrm{xx}} \\
{[4,3 ; 5,6]}\end{array}$ & $\begin{array}{c}2,7 \\
{[2,3 ; 3,0]}\end{array}$ \\
\hline Лептин, нг/мл & $\begin{array}{c}46,7^{x x} \\
{[41,1 ; 54,8]}\end{array}$ & $\begin{array}{c}41,4^{x x} \\
{[37,6 ; 50,1]}\end{array}$ & $\begin{array}{c}18,9 \\
{[13,6 ; 23,2]}\end{array}$ \\
\hline Плацентарный лактоген, мг/л & $\begin{array}{c}8,5^{\text {xx,yyyy }} \\
{[7,3 ; 9,9]}\end{array}$ & $\begin{array}{c}2,5 \\
{[1,4 ; 3,7]}\end{array}$ & $\begin{array}{c}2,1 \\
{[0,9 ; 3,1]}\end{array}$ \\
\hline ПАМГ-1, нг/МЛ & $\begin{array}{c}28,7^{\text {xх,yуyy }} \\
{[24,2 ; 33,0]}\end{array}$ & $\begin{array}{c}12,4 \\
{[8,7 ; 16,5]}\end{array}$ & $\begin{array}{c}10,1 \\
{[7,5 ; 13,2]}\end{array}$ \\
\hline Мочевая кислота, мкмоль/л & $\begin{array}{c}302,3^{\text {хx,yyyy }} \\
{[275,8 ; 336,1]}\end{array}$ & $\begin{array}{c}217,5^{x} \\
{[189,7 ; 241,6]}\end{array}$ & $\begin{array}{c}184,7 \\
{[163,4 ; 207,9]}\end{array}$ \\
\hline ЦЭК, кл/100 мкл & $\begin{array}{c}27^{x x, y y} \\
{[22 ; 33]}\end{array}$ & $\begin{array}{c}21^{x x} \\
{[15 ; 25]}\end{array}$ & $\begin{array}{c}8 \\
{[5 ; 11]}\end{array}$ \\
\hline ФНО-а, пг/мл & $\begin{array}{c}16,6^{\text {xx,yyyy }} \\
{[14,3 ; 19,7]}\end{array}$ & $\begin{array}{c}11,2^{\mathrm{xx}} \\
{[7,5 ; 13,7]}\end{array}$ & $\begin{array}{c}4,9 \\
{[3,6 ; 6,1]}\end{array}$ \\
\hline Агрегация тромбоцитов с коллагеном, \% & $\begin{array}{c}56,2^{\text {xx,yyyy }} \\
{[52,0 ; 59,4]}\end{array}$ & $\begin{array}{c}40,7 \\
{[37,9 ; 44,1]}\end{array}$ & $\begin{array}{c}37,7 \\
{[34,6 ; 40,1]}\end{array}$ \\
\hline ФН, мкг/мл & $\begin{array}{c}347^{x x, y y y} \\
{[321 ; 392]}\end{array}$ & $\begin{array}{c}305^{x x} \\
{[281 ; 332]} \\
\end{array}$ & $\begin{array}{c}219 \\
{[197 ; 242]} \\
\end{array}$ \\
\hline ФРП, пг/мл & $\begin{array}{c}219 \\
{[196 ; 245]}\end{array}$ & $\begin{array}{c}224 \\
{[199 ; 252]}\end{array}$ & $\begin{array}{c}237 \\
{[204 ; 270]}\end{array}$ \\
\hline
\end{tabular}

Примечание. $x$ - статистически значимое отличие c IV группой ( $x-p=0,03 ; x x-p<0,001)$; $y-$ статистически значимое отличие со II группой ( $y-p=0,04 ;$ y $-p=0,02 ;$ yyy $-p=0,01 ;$ yуyy $-p<0,001)$.

$\left(p_{1-2}, p_{1-4}, p_{2-4}<0,001\right)$, при этом нарастание показателя в I группе составило 1,8 раза, во II - 1,3 раза. Уровень ФНО-а в III группе в 30-34 нед по тенденции изменений аналогичен I группе, достоверно превышает значения во II и контрольной группах $\left(p_{2-3^{\prime}}, p_{3-4}<0,001\right)$. Оценка содержания СРБ в III триместре показала достоверное превышение параметра в группах с ПЭ по сравнению co II группой ( $\left.p_{1-2^{\prime}} p_{2-3}<0,001\right)$. Параллельно отмечено повышение в I и III группах количества лейкоцитов, нейтрофилов, функциональной активности лейкоцитов, которая у беременных с ПЭ достоверно выше, чем у женщин с МС без ПЭ ( $\left.p_{1-2^{\prime}} p_{2-3}<0,001\right)$ (табл. 3). У женщин с ПЭ также выявлено статистически значимое повышение тромбоцитарных показателей по сравнению со II и контрольной группами $\left(\mathrm{p}_{1-2^{\prime}}, \mathrm{p}_{1-4^{\prime}}, \mathrm{p}_{2-3^{\prime}}, \mathrm{p}_{3-4}<0,001\right)$.

Выявленный у беременных с ПЭ без сопутствующей соматической патологии и на фоне $\mathrm{MC}$ повышенный уровень мочевой кислоты приобретает значение патологической гиперурикемии $\left(\mathrm{p}_{1-2,} \mathrm{p}_{2-3}<0,001\right)$. Выявлена сильная положительная корреляционная связь между уровнем мочевой кислоты и содержанием ЦЭК, агрега-

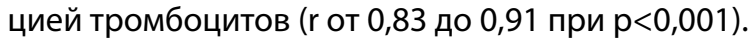

Для объективизации эндотелиальной дисфункции при МС и ПЭ определялись количество ЦЭК, содержание ФН и метаболитов NO в крови. Уже в конце I триместра получены достоверные различия между группами по количеству ЦЭК ( $\left.\mathrm{p}_{1-2}=0,02, \mathrm{p}_{1-4}, \mathrm{p}_{2-4}<0,001\right)$, нарастающие к III триместру. Значение показателя в III группе статистически выше, чем в группе с МС без ПЭ и контроле $\left(p_{2-3^{\prime}} p_{3-4}<0,001 ;\right.$ табл. 1, 3). Изменение концентрации ФН имеет аналогичные тенденции в исследуемых группах. У женщин I, II и III групп уровень метаболитов NO в крови достоверно ниже, чем в контроле ( $<<0,001$ во всех группах), при этом в группах с ПЭ снижение метаболитов NO значительнее, чем при МС без ПЭ.

Нами выявлена сильная положительная корреляционная связь между уровнями инсулина, HOMA-IR и уровнем ФНО-а, агрегацией тромбоцитов, ЦЭК и сильная отрицательная связь с уровнем метаболитов NO ( $r$ от 0,82 до 0,95 при p<0,001), а также положительная связь средней силы между уровнями инсулина, HOMA-IR и индексом активации лейкоцитов ( $\mathrm{r} 0,74$, и 0,69 при $p<0,05)$. 
Таблица 2. Значения метаболических и гормональных показателей у женщин групп сравнения в 30-34 нед гестации (Ме[Q; $\left.\mathrm{Q}_{3}\right]$ )

\begin{tabular}{|c|c|c|c|c|}
\hline Лабораторные показатели & $\begin{array}{c}\text { I группа } \\
(n=50)\end{array}$ & $\begin{array}{c}\text { II группа } \\
(n=32)\end{array}$ & $\begin{array}{c}\text { III rрyпna } \\
(n=44)\end{array}$ & $\begin{array}{c}\text { IV группа } \\
(n=30)\end{array}$ \\
\hline Глюкоза, ммоль/л & $\begin{array}{c}4,4 \\
{[4,1 ; 4,8]}\end{array}$ & $\begin{array}{c}4,1 \\
{[3,7 ; 4,4]}\end{array}$ & $\begin{array}{c}4,1 \\
{[3,8 ; 4,5]}\end{array}$ & $\begin{array}{c}4,3 \\
{[3,9 ; 4,8]}\end{array}$ \\
\hline Инсулин, пмоль/мл & $\begin{array}{c}177,7^{x, y y y, z z} \\
{[166,8 ; 188,2]}\end{array}$ & $\begin{array}{c}115,4^{x} \\
{[105,4 ; 124,3]}\end{array}$ & $\begin{array}{c}152,7^{x, y y y} \\
{[140,3 ; 162,9]}\end{array}$ & $\begin{array}{c}67,1 \\
{[56,1 ; 79,3]}\end{array}$ \\
\hline HOMA-IR & $\begin{array}{c}4,88^{x, y y y, z z} \\
{[4,39 ; 5,54]}\end{array}$ & $\begin{array}{c}2,98^{x} \\
{[2,63 ; 3,42]}\end{array}$ & $\begin{array}{c}3,85^{x, y y y} \\
{[3,48 ; 4,28]}\end{array}$ & $\begin{array}{c}1,69 \\
{[1,32 ; 2,14]}\end{array}$ \\
\hline ОХ, ммоль/л & $\begin{array}{c}7,17^{\text {x,yy }} \\
{[6,98 ; 7,28]}\end{array}$ & $\begin{array}{c}6,94^{x} \\
{[6,76 ; 7,13]}\end{array}$ & $\begin{array}{c}7,05^{x} \\
{[6,84 ; 7,23]}\end{array}$ & $\begin{array}{c}5,92 \\
{[5,53 ; 6,42]}\end{array}$ \\
\hline ТГ, ммоль/л & $\begin{array}{c}3,34^{x, y} \\
{[3,18 ; 3,51]}\end{array}$ & $\begin{array}{c}3,19^{x} \\
{[3,02 ; 3,31]}\end{array}$ & $\begin{array}{c}3,24^{x} \\
{[3,09 ; 3,38]}\end{array}$ & $\begin{array}{c}2,21 \\
{[2,01 ; 2,47]}\end{array}$ \\
\hline ЛПВП, ммоль/л & $\begin{array}{c}0,87^{x, y y y, z z} \\
{[0,83 ; 0,91]}\end{array}$ & $\begin{array}{c}0,97^{x} \\
{[0,91 ; 1,03]}\end{array}$ & $\begin{array}{c}1,02^{\mathrm{x}} \\
{[0,98 ; 1,06]}\end{array}$ & $\begin{array}{c}1,15 \\
{[1,09 ; 1,21]}\end{array}$ \\
\hline ТГ/ЛПВП & $\begin{array}{c}3,84^{x, y y y, z z} \\
{[3,62 ; 3,99]}\end{array}$ & $\begin{array}{c}3,29^{x} \\
{[3,05 ; 3,59]}\end{array}$ & $\begin{array}{c}3,18^{x} \\
{[2,95 ; 3,42]}\end{array}$ & $\begin{array}{c}1,91 \\
{[1,68 ; 2,25]}\end{array}$ \\
\hline KA & $\begin{array}{c}7,3^{x, y y y, z z} \\
{[6,7 ; 7,7]}\end{array}$ & $\begin{array}{c}6,2^{x} \\
{[5,8 ; 6,8]}\end{array}$ & $\begin{array}{c}5,9^{\mathrm{x}} \\
{[5,5 ; 6,3]}\end{array}$ & $\begin{array}{c}4,1 \\
{[3,6 ; 4,7]}\end{array}$ \\
\hline Мочевая кислота, мкмоль/л & $\begin{array}{c}429,8^{x, y y y, z z} \\
{[401,4 ; 462,1]}\end{array}$ & $\begin{array}{c}286,9^{x} \\
{[258,5 ; 312,4]}\end{array}$ & $\begin{array}{c}371,7^{x, y y y} \\
{[342,4 ; 395,8]}\end{array}$ & $\begin{array}{c}245,9 \\
{[218,6 ; 269,3]}\end{array}$ \\
\hline Лептин, нг/мл & $\begin{array}{c}86,2^{\text {x,yyy }} \\
{[81,9 ; 92,3]}\end{array}$ & $\begin{array}{c}59,8^{x} \\
{[51,3 ; 67,7]}\end{array}$ & $\begin{array}{c}83,9^{x, y y y} \\
{[76,3 ; 88,1]}\end{array}$ & $\begin{array}{c}34,6 \\
{[29,2 ; 40,8]}\end{array}$ \\
\hline Плацентарный лактоген, мг/л & $\begin{array}{c}14,6^{x, y y y, z z} \\
{[13,6 ; 15,3]}\end{array}$ & $\begin{array}{c}8,6 \\
{[7,5 ; 9,8]}\end{array}$ & $\begin{array}{c}12,5^{\text {x,yyy }} \\
{[11,2 ; 13,4]}\end{array}$ & $\begin{array}{c}7,4 \\
{[6,2 ; 8,7]}\end{array}$ \\
\hline ПАМГ-1, нг/мл & $\begin{array}{c}52,6^{x, y y y, z} \\
{[47,4 ; 58,1]}\end{array}$ & $\begin{array}{c}32,1^{x} \\
{[27,8 ; 36,9]}\end{array}$ & $\begin{array}{c}47,4^{\text {x,yyy }} \\
{[42,2 ; 51,8]}\end{array}$ & $\begin{array}{c}21,9 \\
{[18,3 ; 26,1]}\end{array}$ \\
\hline
\end{tabular}

Примечание. $x$ - статистически значимое отличие c IV группой $(x-p<0,001) ; y-$ статистически значимое отличие со II группой (y - p=0,03, уу $-p=0,01$, ууу $-p<0,001) ; z-$ статистически значимое отличие $c$ III группой $(z-p=0,01, z z-p<0,001)$.

Таблица 3. Значения гематологических показателей, маркеров провоспалительного состояния и эндотелиальной дисфункции у женщин групп сравнения в 30-34 нед гестации $\left(\mathrm{Me}\left[\mathrm{Q}_{1} ; \mathrm{Q}_{3}\right]\right)$

\begin{tabular}{|c|c|c|c|c|}
\hline Лабораторные показатели & $\begin{array}{c}\text { rpynna } \\
(n=50)\end{array}$ & $\begin{array}{c}\text { II rрyпna } \\
(n=32)\end{array}$ & $\begin{array}{c}\text { III rрyпna } \\
(n=44)\end{array}$ & $\begin{array}{c}\text { IV rрyпnа } \\
(n=30)\end{array}$ \\
\hline Кол-во тромбоцитов, x10\%/л & $\begin{array}{c}207^{x, y y, z z} \\
{[197 ; 218]} \\
\end{array}$ & $\begin{array}{c}259^{x} \\
{[245 ; 273]}\end{array}$ & $\begin{array}{c}232^{x, y y} \\
{[221 ; 243]}\end{array}$ & $\begin{array}{c}283 \\
{[278 ; 308]} \\
\end{array}$ \\
\hline Средний объем тромбоцита, фл & $\begin{array}{c}9,94^{x, y y, z z} \\
{[9,59 ; 10,33]}\end{array}$ & $\begin{array}{c}8,16^{x} \\
{[7,82 ; 8,41]}\end{array}$ & $\begin{array}{c}8,92^{x, y y} \\
{[8,63 ; 9,25]}\end{array}$ & $\begin{array}{c}7,46 \\
{[7,21 ; 7,69]}\end{array}$ \\
\hline Фракция незрелых тромбоцитов, \% & $\begin{array}{c}8,9^{x, y y, z} \\
{[7,6 ; 10,5]}\end{array}$ & $\begin{array}{c}3,5 \\
{[2,4 ; 6,2]}\end{array}$ & $\begin{array}{c}6,9^{x, y} \\
{[5,1 ; 8,3]}\end{array}$ & $\begin{array}{c}2,9 \\
{[1,7 ; 4,4]}\end{array}$ \\
\hline Агрегация тромбоцитов с коллагеном, \% & $\begin{array}{c}68,9^{x, y y, z z} \\
{[65,8 ; 71,5]}\end{array}$ & $\begin{array}{c}55,5^{\mathrm{x}} \\
{[51,3 ; 58,6]}\end{array}$ & $\begin{array}{c}62,3^{x, y y} \\
{[59,1 ; 65,5]}\end{array}$ & $\begin{array}{c}47,4 \\
{[44,1 ; 50,2]} \\
\end{array}$ \\
\hline Кол-во лейкоцитов, M (SD); ×10%л & $10,9(1,7)^{x, y y}$ & $8,1(1,3)$ & $9,6(1,5)^{x}$ & $6,8(1,3)$ \\
\hline Кол-во нейтрофилов, M (SD); ×109/л & $8,4(1,4)^{x, y y}$ & $5,5(0,9)$ & $7,3(1,1)^{x, y}$ & $4,8(0,8)$ \\
\hline Индекс активации лейкоцитов, M (SD); \% & $93(12)^{x, y y, z z}$ & $44(8)^{x}$ & $68(9)^{x, y y}$ & $0 \pm 9$ \\
\hline ЦЭК, кл/100 мкл & $\begin{array}{c}55^{x, y y, z z} \\
{[51 ; 59]}\end{array}$ & $\begin{array}{c}34^{x} \\
{[29 ; 38]}\end{array}$ & $\begin{array}{c}45^{x, y y} \\
{[40 ; 49]}\end{array}$ & $\begin{array}{c}22 \\
{[16 ; 27]}\end{array}$ \\
\hline ФНО-а, пг/мл & $\begin{array}{c}30,3^{x, y y, z z} \\
{[27,7 ; 32,4]}\end{array}$ & $\begin{array}{c}14,7 \\
{[11,2 ; 17,1]}\end{array}$ & $\begin{array}{c}22,8^{x, y y} \\
{[19,6 ; 26,3]}\end{array}$ & $\begin{array}{c}12,2 \\
{[10,7 ; 14,8]} \\
\end{array}$ \\
\hline СРБ, мкГ/мЛ & $\begin{array}{c}33,2^{x, y y, z z} \\
{[29,8 ; 36,9]}\end{array}$ & $\begin{array}{c}15,1 \\
{[11,6 ; 18,2]} \\
\end{array}$ & $\begin{array}{c}24,7^{x, y y} \\
{[21,4 ; 27,6]}\end{array}$ & $\begin{array}{c}13,5 \\
{[9,1 ; 15,9]} \\
\end{array}$ \\
\hline$Ф Н$, мкг/мл & $\begin{array}{c}496^{x, y y, z z} \\
{[472 ; 521]}\end{array}$ & $\begin{array}{c}367 \\
{[341 ; 394]}\end{array}$ & $\begin{array}{c}449 x, y y \\
{[422 ; 465]}\end{array}$ & $\begin{array}{c}349 \\
{[323 ; 376]} \\
\end{array}$ \\
\hline Метаболиты NO, мкмоль/л & $\begin{array}{c}23,7^{x, y y, z z} \\
{[20,8 ; 26,1]}\end{array}$ & $\begin{array}{c}35,7^{x} \\
{[33,4 ; 38,6]}\end{array}$ & $\begin{array}{c}29,7^{x, y y} \\
{[26,4 ; 31,9]}\end{array}$ & $\begin{array}{c}44,6 \\
{[40,4 ; 47,5]}\end{array}$ \\
\hline ФРП, пг/мл & $\begin{array}{c}368^{x} \\
{[335 ; 412]}\end{array}$ & $\begin{array}{c}395^{x} \\
{[354 ; 433]}\end{array}$ & $\begin{array}{c}376^{x} \\
{[338 ; 415]}\end{array}$ & $\begin{array}{c}582 \\
{[532-626]}\end{array}$ \\
\hline
\end{tabular}

Примечание. $x$ - статистически значимое отличие c IV группой $(x-p<0,001) ; y-$ статистически значимое отличие со II группой $(y-p=0,01$, уу $-p<0,001) ; z$ - статистически значимое отличие с III группой $(z-p=0,01, z z-p<0,001)$. 
Дополнительные результаты исследования

В связи с дискуссионным взглядом на роль эмбрио(фето)плацентарного комплекса в развитии ПЭ особый интерес вызывает частота реализации ПН в группах сравнения. Показано, что данное осложнение беременности диагностировалось примерно одинаково часто, без статистических различий, среди женщин с ПЭ без сопутствующей соматической патологии, ПЭ на фоне МС и у женщин с МС без ПЭ - 40,9 (18/44), 44,0 (22/50) и 34,4\% $(11 / 32)$ наблюдений соответственно ( $x 2=0,75, \mathrm{p}=0,68)$. ПН II-III степени (ЗРП на 3-4 нед и более) встречалась уженщин I $(36,0 \%-18 / 50)$ и III $(34,1 \%$ - 15/44) групп чаще, чем во II $(28,1 \%$ - 9/32) в 1,3 и 1,2 раза соответственно, однако также без статистически значимых отличий: $\mathrm{X}^{2}{ }_{1-3}=0,04$, $p_{1-3}=0,85 ; x_{2-3}^{2}=0,09, p_{2-3}=0,76 ; x_{1-2}^{2}=0,25, p_{1-2}=0,61$.

К одним из факторов, отражающих состояние фетоплацентарного комплекса (ФПК), относится уровень ФРП. Оценка содержания фактора роста в конце I триместра беременности не показала различий в исследуемых группах ( $\left.p_{1-2}=0,88, p_{1-4}=0,66, p_{2-4}=0,79\right)$. В 30-34 нед гестации отмечено значимое снижение концентрации ФРП в I, II, III группах по сравнению с контролем ( $\mathrm{p}_{1-2}=0,34$, $\left.\mathrm{p}_{1-3}=0,52, \mathrm{p}_{2-3}=0,70, \mathrm{p}_{1-4^{\prime}} \mathrm{p}_{2-4^{\prime}} \mathrm{p}_{3-4}<0,001\right)$.

Для полноты характеристики результатов исследования нами представлены методы родоразрешения и перинатальные исходы в группах сравнения. Основными показаниями к родоразрешению беременных I и III групп путем операции кесарева сечения явились нарастание тяжести ПЭ, патология ФПК: абдоминальным методом родоразрешены 78\% (39/50) и 75\% (33/44) беременных I и III групп соответственно $\left(x^{2}=0,12 ; p=0,73\right)$. Вo II группе оперативное родоразрешение выполнено у 31,2\% (10/32) беременных в основном по совокупности показаний (нарушение состояния плода, несвоевременное излитие околоплодных вод, тазовое предлежание, рубец на матке, неправильное положение плода) $-\mathrm{X}_{1-2}^{2}=17,73, \mathrm{p}_{1-2}<0,001 ; \mathrm{X}_{2-3}^{2}=14,43$, $\mathrm{p}_{2-3}<0,001$. B IV группе $100 \%$ (30/30) беременных родоразрешены через естественные родовые пути. Средняя масса новорожденных составила 2260 (320), 2905 (285), 2350 (307), $3320(235)$ г $\left(p_{1-2}=0,04, p_{1-3}=0,81, p_{1-4}=0,01, \quad p_{2-3}=0,04\right.$, $\left.\mathrm{p}_{2-4}=0,15, \mathrm{p}_{3-4}=0,01\right)$, индекс Кетле I (г/см) и пондераловый

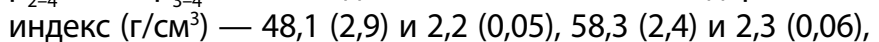
$49,9(2,7)$ и 2,2 (0,04), 61,3 (2,6) и 2,4 $(0,06)$ - соответственно I, II, III, IV группам (для индекса Кетле I - $\mathrm{p}_{1-2}=0,01, \mathrm{p}_{1-3}=0,65$, $\mathrm{p}_{1-4}<0,001, \mathrm{p}_{2-3}=0,03, \mathrm{p}_{2-4}=0,32, \mathrm{p}_{3-4}<0,001$; для пондералового индекса $-\mathrm{p}_{1-2}=0,17, \mathrm{p}_{1-3}=0,92, \mathrm{p}_{1-4}=0,01, \mathrm{p}_{2-3}=0,15$, $\left.\mathrm{p}_{2-4}=0,25, \mathrm{p}_{3-4}=0,01\right)$. Без асфиксии, в асфиксии легкой и средней степени тяжести родились соответственно: 48,44 и 8\% новорожденных в I группе; 75, 25\% - во II группе; 52, 39 и $9 \%$ - в III группе (без асфиксии - $x_{1-2}^{2}=5,86, p_{1-2}=0,02$; $\left.x_{1-3}^{2}=0,17, p_{1-3}=0,68 ; \quad x_{2-3}^{2}=4,05, p_{2-3}=0,04\right) ; 100 \%$ новорожденных IV группы родились без асфиксии. На второй этап выхаживания переведены 34\% новорожденных I группы, $9 \%$ новорожденных II группы, 32\% - III группы $\left(X_{1-2}^{2}=6,42\right.$, $\left.\mathrm{p}_{1-2}=0,01 ; \mathrm{x}_{1-3}^{2}=0,05, \mathrm{p}_{1-3}=0,82 ; \mathrm{x}_{2-3}^{2}=5,37, \mathrm{p}_{2-3}=0,02\right)$. Морфофункциональные характеристики новорожденных и показания к переводу на последующий этап лечения обусловлены тяжестью ПЭ и ПН.

Нежелательные явления

При проведении исследования нежелательных явлений выявлено не было.

\section{ОБСУЖДЕНИЕ}

Резюме основного результата исследования

Результаты исследования позволили выявить сходство между ПЭ без сопутствующей соматической патологии и МС (без ПЭ и с реализацией ПЭ) по диагностике таких состояний, характерных для МС, как патологические типы суточной вариабельности АД, гестационное сонное апноэ, инсомния, что дополняется статистически значимым нарастанием лабораторных изменений, играющих ключевую роль в патогенезе МС вне беременности, таких как диабетогенные и атерогенные нарушения с развитием патологических ИР, ГИ и лептинемии, гиперактивация эндотелиально-тромбоцитарного звена, тромботический и воспалительный статус, висцеральный тип жироотложения, гиперурикемия, гиперсимпатикотония, что отражает важность дисметаболических механизмов в патогенезе ПЭ.

Обсуждение основного результата исследования

Частота реализации ПЭ среди женщин с МС, которая составила $61 \%$, более чем в десятки раз превышает среднепопуляционный уровень развития данного осложнения, что, несомненно, отражает связь существующих метаболических нарушений с развитием ПЭ.

Клинический анализ течения беременности у женщин групп сравнения показал наличие патологических типов вариабельности АД (non-dipper, night-picker), характерных для эссенциальной АГ и МС, не только в I и II группах, но и у женщин с ПЭ без сопутствующей соматической патологии. При этом патологические типы вариабельности АД тесно взаимосвязаны с синдромом обструктивного апноэ сна (отдельный клинический вариант МС), который сопровождается периодами гипоксии, окислительным стрессом и выбросом катехоламинов в ночное время [16]. Аналогичные нарушения дыхания при беременности, обозначаемые как гестационное сонное апноэ, формируются как у женщин с МС, так и в группе с ПЭ без сопутствующей соматической патологии, что, по-видимому, обусловлено срывом однотипных механизмов адаптации к возникающим при беременности изменениям дыхательной системы (смещение диафрагмы вверх растущей маткой, снижение на 20\% функциональной остаточной емкости легких, повышенное кровенаполнение сосудов слизистой носа, ротоглотки, гортани под действием эстрогенов, ухудшение механики дыхания в результате увеличения и нагрубания молочных желез) $[15,16]$. Статистически более частая встречаемость инсомнии в группах с ПЭ по сравнению со II группой наглядно отражает сохранение центральных механизмов ауторегуляции у женщин с МС без ПЭ, несмотря на сниженный резерв адаптации. В то же время отсутствие у беременных контрольной группы патологических типов вариабельности АД, гестационного сонного апноэ, инсомнии отражает сбалансированную работу адаптационных механизмов.

Интерес вызывает динамика накопления и локусы распределения жировой ткани у беременных групп сравнения. Особо важно, что ППЖ (висцеральный, важнейший компонент МС), имеющий высокую метаболическую активность, был значительно выражен к III триместру у женщин III группы, не имеющих догестационных 
метаболических нарушений. Преобладание тППЖ над тПКЖ в I и III группах, отражающееся в ИЖБС, указывает на общую закономерность отложения жира при ПЭ без сопутствующей соматической патологии и ПЭ на фоне МС и важную роль ППЖ в развитии ПЭ.

Не менее важным звеном патогенеза МС являются ИР и ГИ $[2,3]$, что подтверждается полученными уровнями инсулина и HOMA-IR в I и II группах, при этом реализация ПЭ сопровождалась более выраженным нарастанием показателей в динамике. Участие ИР в развитии ПЭ отражают и результаты в III группе, где у исходно нескомпрометированных по метаболическим нарушениям женщин уровни инсулина и HOMA-IR статистически значимо выше, чем у женщин с МС без ПЭ, и сопоставимы с ПЭ на фоне МС. Следовательно, физиологическая ИР и компенсаторная ГИ, характерные для «нормы беременности», приобретают в III группе патологический характер с реализацией в ПЭ [10].

При физиологической беременности в развитии и поддержании ИР, наряду с основным фактором действия - плацентарными контринсулярными гормонами, принимают участие повышенные уровни атерогенных фракций липидов, необходимые для энергообеспечения матери $[10,17]$. Однако выявленные в группах с ПЭ данные сдвиги метаболизма нарастают значительно, способствуя формированию патологических ИР и ГИ, эндотелиально-гемостазиологической дисфункции, провоспалительному статусу (табл. 2, 3). К аналогичным изменениям ведут характерные для MC гиперлептинемия и лептинорезистентность, вызывающие также формирование гиперсимпатикотонии и повышение АД $[2,3,18]$. Участие лептина в патогенезе ПЭ подтверждается достоверно более высокими уровнями показателя в I и III группах по сравнению со II и контрольной группами.

Специфическим для беременности контринсулярным гормоном является ПЛ [10]. Его повышение при беременности, направленное на формирование физиологической ИР и ГИ, по своей сути сопоставимо с повышением контринсулярных гормонов при МС. Выявленное значительное нарастание уровня ПЛ у женщин в группах с ПЭ указывает на его роль в формировании патологических ИР и ГИ. Схожую динамику имела концентрация ПАМГ-1, синтезируемого дифференцированными клетками децидуальной оболочки. Данный пептид модулирует активность инсулиноподобного фактора роста (ИФР), специфически связываясь с ним и усиливая тем самым ИР и ГИ. Регуляция митогенных функций ИФР ограничивает опухолеподобную инвазивность трофобласта $[9,10]$. Выявленные изменения уровней ФНО-а, СРБ, повышение количества лейкоцитов, нейтрофилов и, что особенно важно, функциональной активности лейкоцитов у женщин I и III групп свидетельствуют об активации иммунного ответа при формировании ПЭ. Адаптивная антиоксидантная роль мочевой кислоты при физиологической беременности в условиях гиперурикемии сменяется на альтеративную с повреждением эндотелия и гиперактивацией тромбоцитов [19]. Данное положение подтверждается выявленной сильной положительной корреляционной связью между уровнем мочевой кислоты и ЦЭК, агрегацией тромбоцитов.

Мишенью для всех вышеперечисленных патологических изменений выступает эндотелий сосудистой стенки. Повреждение гликокаликса, мембраны, эндоплазматического ретикулума, митохондрий эндотелиоцита вызывает его функциональную дестабилизацию и гибель $[20,21]$. В результате в крови повышается количество ЦЭК, при этом наличие у женщин МС определяет достоверность различий с контролем в конце I триместра, а присоединение патогенетического компонента ПЭ обосновывает столь высокие значения показателя как при ПЭ без сопутствующей соматической патологии, так и на фоне МС. Повышенная концентрация ФН в группах с ПЭ, выделяющегося при активации и повреждении эндотелия, также свидетельствует об эндотелиальной дисфункции. В результате нарастания при ПЭ без сопутствующей соматической патологии и на фоне МС патологических ИР и ГИ, эндотелиальной дисфункции нарушается синтез эндотелиоцитами NO - важнейшего вазодилятатора и вазопротектора в организме, возникают схожие условия для гипертрофии и ремоделирования сосудистой стенки и миокарда, в результате повышается общее периферическое сосудистое сопротивление и формируется артериальная гипертензия.

Одновременно с эндотелиальной дисфункцией возникает протромботическое состояние, характерное как для MC, так и для ПЭ. Более выраженный характер активации тромбоцитарного звена у женщин с ПЭ, проявляющийся гиперагрегацией, увеличением объема тромбоцита и фракции незрелых тромбоцитов, несомненно, способствует формированию тяжелых форм ПЭ, а также развитию HELLP-синдрома при ее осложненном течении.

Формирование ИР, ГИ, лептинемии, дислипидемии при физиологической гестации в качестве механизмов гестационной адаптации к росту и развитию плода, их патологическое нарастание с ранних сроков осложненной ПЭ беременности, результаты корреляционного анализа определяют первичность дисметаболических механизмов относительно других патогенетических звеньев ПЭ - антиангиогенного состояния, эндотелиальной дисфункции, гемостазиологических и провоспалительных изменений, вегетативного дисбаланса.

Анализ динамики концентрации ФРП с конца I триместра беременности свидетельствует об отсутствии эмбрио(фето)плацентарной дисфункции в группах женщин с MC, что подтверждается сопоставимостью уровней ФРП с контролем. В 30-34 нед беременности снижение содержания ФРП связано не с манифестацией ПЭ, а с развитием ПН, особенно с ЗРП ІІ-ІІІ степени. В то же время ПН была диагностирована после 28 нед гестации, что не соответствует плацентарной теории развития ПЭ, согласно которой пусковым механизмом является ранняя эмбриоплацентарная дисфункция с ишемией плаценты. Полученные данные согласуются с существующим в литературе мнением о вторичности формирования ПН в ответ на гемодинамические изменения при ПЭ [19]. Сопоставление уровня ФРП со сроками диагностики ПН подтверждает участие плацентарной дисфункции лишь на поздних этапах формирования ПЭ.

Как было отмечено, предпосылки всех перечисленных изменений уже изначально заложены в компенсаторно-приспособительных процессах физиологической беременности, что обеспечивает пластическое и энергетическое жизнеобеспечение плода (рис. 1). 


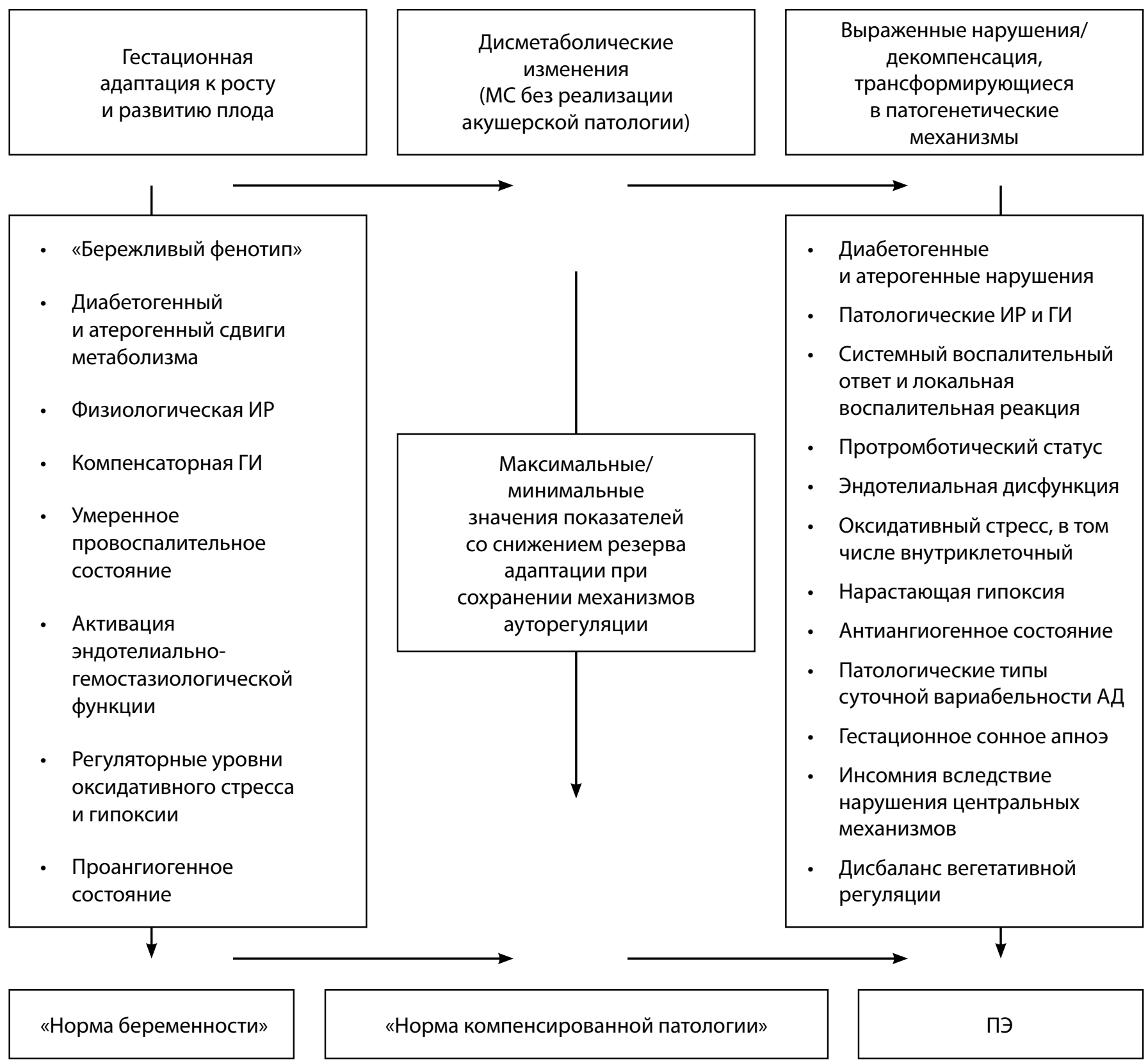

Рис. 1. Метаболические изменения и дисметаболические нарушения при физиологической и осложненной преэклампсией беременности.

Нарастание изменений в рамках «нормы компенсированной патологии» вызывает схожие с МС метаболические нарушения и снижение резерва адаптации, но максимальное напряжение сохраненных механизмов ауторегуляции обеспечивает благоприятный гестационный и перинатальный исходы. В свою очередь, наличие выраженных дестабилизирующих эпигенетических, наследственных, экологических факторов, стигматизация образа жизни, пищевого поведения приводят к нарастанию дисметаболических нарушений и ассоциированных с ними механизмов, с последующей клинической реализацией ПЭ.

\section{Ограничения исследования}

В исследовании оценивались метаболические нарушения у женщин с ПЭ без сопутствующей соматической патологии и ПЭ на фоне МС, в связи с чем для повышения репрезентативности полученных данных необходимо изучение указанных нарушений при ПЭ, сочетающейся с другой экстрагенитальной патологией.

\section{ЗАКЛЮЧЕНИЕ}

Метаболические изменения при физиологической беременности, направленные на жизнеобеспечение плода и трансформирующиеся при наличии факторов риска в патогенетические механизмы ПЭ, а также высокая частота манифестации ПЭ (61\%) у женщин с МС, схожесть выявленных при ПЭ и МС изменений свидетельствуют о важной роли метаболических нарушений в реализации ПЭ.

Углубленное изучение роли дисметаболических механизмов в развитии ПЭ в перспективе позволит предложить качественно иные подходы в вопросах предикции и превенции данного патологического состояния, стратификации беременных по группам риска, выбора врачебной тактики и лечения одного из самых грозных осложнений гестации. 


\section{ДОПОЛНИТЕЛЬНАЯ ИНФОРМАЦИЯ}

Источники финансирования. Исследование выполнено с использованием ресурсов Перинатального центра ГБУз «СОКБ им В.Д. Середавина» г.о. Самара.

Конфликт интересов. Авторы декларируют отсутствие явных и потенциальных конфликтов интересов, связанных с содержанием настоящей статьи.

Участие авторов. Липатов И.С. - концепция и дизайн исследования, написание текста, редактирование; Тезиков Ю.В. - концепция и дизайн исследования, сбор и обработка материала, статистическая обработка данных, редактирование рукописи статьи; Азаматов А.P. сбор и обработка материала, статистическая обработка данных, написание текста. Все авторы одобрили финальную версию статьи перед публикацией, выразили согласие нести ответственность за все аспекты работы, подразумевающую надлежащее изучение и решение вопросов, связанных с точностью или добросовестностью любой части работы.

Благодарности. За помощь в организации исследования благодарим заместителя главного врача по акушерству и гинекологии ГБУЗ «СОКБ им В.Д. Середавина» Тезикову Т.А.

\section{СПИСОК ЛИТЕРАТУРЫ | REFERENCES}

1. Информационный бюллетень ВОЗ «Ожирение и избыточный вес». Дата обновления 16.02.2018. [WHO's fact sheets «Obesity and overweight». Update date 16.02.2018. (In Russ.)]. Доступ по: http://www.who.int/mediacentre/factsheets/fs311/ru/. Ссылка активна на: 26.02.2020.

2. Nolan CJ, Prentki M. Insulin resistance and insulin hypersecretion in the metabolic syndrome and type 2 diabetes: Time for a conceptual framework shift. Diabetes Vasc Dis Res. 2019;16(2):118-127. doi: https://doi.org/10.1177/1479164119827611

3. Полозова Э.И., Пузанова Е.В., Сеськина А.А. Особенности артериальной гипертензии у больных с метаболическими нарушениями // Современные проблемы науки и образования. 2019. — №3. — C. 179-190. [Polozova Ehl, Puzanova EV, Ses'kina AA. Peculiarities of arterial hypertension in patients with metabolic disorders. Sovremennye problemy nauki i obrazovaniya. 2019;3:179-190. (In Russ.)].

4. Тарасова О.А., Чулков В.С., Синицын С.П., и др. Факторы кардиометаболического риска у женщин с анамнезом артериальной гипертензии во время беременности // Артериальная гипертензия. - 2019. - Т. 25. - №1. - С. 97-104. [Tarasova OA, Chulkov VS, Sinitsyn SP, et al. Cardiometabolic risk factors in women with a history of hypertension during pregnancy. Arterial'naya gipertenziya. 2019;25(1):97-104. (In Russ.)]. doi: https://doi.org/10.18705/1607-419X-2019-25-1-97-104

5. Saxena T, Ali AO, Saxena M. Pathophysiology of essential hypertension: an update. Expert Rev Cardiovasc Ther. 2018;16(12):879-887. doi: https://doi.org/10.1080/14779072.2018.1540301

6. Общероссийская общественная организация содействия профилактике и лечению артериальной гипертензии «Антигипертензивная Лига». Алгоритмы ведения пачиента с артериальной гипертензией гипертоническим кризом. Санкт-Петербург; 2019. 90 с. [All-Russian public organization. Assistance in the prevention and treatment of arterial hypertension «Antihypertensive League». Algorithms for managing a patient with arterial hypertension, hypertensive crisis. First edition. St. Petersburg; 2019. 90 p. (In Russ.)].

7. Белинина А.А., Яворская С.Д., Бельницкая О.А. Возможность профилактики тяжелых преэклампсий за счет индивидуальной прегравидарной подготовки // Аспирантский вестник Поволжья. - 2016. — №5-6. — C. 50-54. [Belinina AA, Yavorskaya SD, Bel'nitskaya OA. The possibility of preventing severe preeclampsia due to individual pregravid preparation. Aspirantskii vestnik Povolzh'ya. 2016;5-6:50-54. (In Russ.)].

8. Kodogo V, Azibani F, Sliwa K. Role of pregnancy hormones and hormonal interaction on the maternal cardiovascular system: a literature review. Clin Res Cardiol. 2019;108(8):831-846. doi: https://doi.org/10.1007/s00392-019-01441-x

9. Фролова Н.А. Обоснование патогенетической связи эмбрио(фето) плацентарной недостаточности с ранней и поздней преэклампсией // Аспирантский вестник Поволжья. - 2015. №1-2. - C. 44-53. [Frolova NA. The evidence of pathogenetic link between embrio(feto)-placental insufficiency with early and late preeclampsia. Aspirantskii vestnik Povolzh'ya. 2015;1-2:44-53. (In Russ.)].

10. Napso T, Yong HEJ, Lopez-Tello J, Sferruzzi-Perri AN. The role of placental hormones in mediating maternal adaptations to support pregnancy and lactation. Front Physiol. 2018. doi: https://doi.org/10.3389/fphys.2018.01091

11. Гипертензивные расстройства во время беременности, в родах и послеродовом периоде. Преэклампсия. Эклампсия. Клинические рекомендации (Протокол лечения). 2016. [National clinical guidelines «Hypertensive disorders during pregnancy, childbirth and postpartum. Pre-eclampsia and Eclampsia». 2016. (In Russ.)]. Доступно по: http://www.rokb.ru/sites/default/files/pictures/ gipertenzivnye_rasstroystva_vo_vremya_beremennosti_v_rodah_i_ poslerodovom_periode._preeklampsiya._eklampsiya.pdf. Ссылка активна на 25.08.2020.

12. Стрижаков А.Н., Тезиков Ю.В., Липатов И.С., и др. Стандартизация диагностики и клиническая классификация хронической плацентарной недостаточности // Вопросы гинекологии, акушерства и перинатологии. - 2014 - Т. 13. - №3. C. 5-12. [Strizhakov AN, Tezikov YuV, Lipatov IS, et al. Standardization of diagnosis and clinical classification of chronic placental insufficiency. Voprosy ginekologii, akusherstva i perinatologii. 2014;13(3):5-12. (In Russ.)].

13. Altikardes ZA, Kayikli A, Korkmaz H, et al. A novel method for dipper/non-dipper pattern classification in hypertensive and non-diabetic patients. Technol Heal Care. 2019;27(1):47-57 doi: https://doi.org/10.3233/THC-199006

14. Калачин К.А., Пырегов А.В., Шмаков Р.Г. Гестационное сонное апноэ. Связь беременности и преэклампсии с синдромом обструктивного апноэ сна // Альманах клинической медицины. 2019. - T. 47. - №3. - C. 266-275. [Kalachin KA, Pyregov AV, Shmakov RG. Gestational sleep apnea. The relationship of pregnancy and preeclampsia with obstructive sleep apnea syndrome. Al'manakh klinicheskoi meditsiny. 2019;47(3):266-275. (In Russ.)]. doi: https://doi.org/10.18786/2072-0505-2019-47-03

15. Karan S, Ginosar Y. Gestational sleep apnea: have we been caught napping? Int J Obstet Anesth. 2016;26(1):1-3. doi: https://doi.org/10.1016/j.joa.2016.03.001

16. Тезиков Ю.В., Липатов И.С. Результаты применения карбогенотерапии для профилактики плацентарной недостаточности // Российский вестник акушера-гинеколога. 2011. - T. 11. — №5. - C. 71-77. [Tezikov YuV, Lipatov IS. Results of using carbogen therapy to prevent placental insufficiency. Rossiiskii vestnik akushera-ginekologa. 2011;11(5):71-77. (In Russ.)].

17. Chen X, Stein TP, Steer RA, Scholl TO. Individual free fatty acids have unique associations with inflammatory biomarkers, insulin resistance and insulin secretion in healthy and gestational diabetic pregnant women. BMJ Open Diabetes Res Care. 2019;7(1):e000632. doi: https://doi.org/10.1136/bmjdrc-2018-000632

18. Echeverria C, Eltit F, Santibanez JF, et al. Endothelial dysfunction in pregnancy metabolic disorders. Biochim Biophys Acta Mol Basis Dis. 2020;1866(2):165414. https://doi.org/10.1016/j.bbadis.2019.02.009.

19. Moore TA, Ahmad IM, Schmid KK. Oxidative stress levels throughout pregnancy, at birth, and in the neonate. Biol Res Nurs. 2019;21(5):485-494. https://doi.org/10.1177/1099800419858670.

20. Липатов И.С., Тезиков Ю.В., Санталова Г.В., Овчинникова М.А. Профилактика рецидивов герпетической инфекции у беременных и внутриутробного инфицирования плода вирусом простого герпеса // Российский вестник акушера-гинеколога. - 2014. T. 14. - №4. - C. 63-68. [Lipatov IS, Tezikov YuV, Santalova GV, Ovchinnikova MA. Prevention of recurrent herpetic infection in pregnant women and intrauterine infection of the fetus with the herpes simplex virus. Rossiiskii vestnik akushera-ginekologa. 2014;14(4):63-68. (In Russ.)].

21. Нагоев Т.М., Муминова К.Т., Ходжаева 3.С., и др. Материнская гемодинамика и преэклампсия // Акушерство и гинекология. 2020. — №1. - C. 5-11. [Nagoev TM, Muminova KT, Khodzhaeva ZS et al. Maternal hemodynamics and preeclampsia. Akusherstvo i ginekologiya. 2020;(1):5-11. (In Russ.)]. doi: https://doi.org/10.18565/aig.2020.1.5-11 


\section{ИНФОРМАЦИЯ ОБ АВТОРАХ [AUTHORS INFO]:}

*Липатов Игорь Станиславович, д.М.Н., професcop [Igor S. Lipatov, MD, PhD, Professor]; адрес: Pocсия, 443099, Самара, ул. Чапаевская, д. 89 [address: 89 Chapaevskaya street, 4430099 Samara, Russia]; ORCID: https://orcid.org/0000-0001-7277-7431; Researcher ID: C-5060-2018; Scopus Author ID: 6603787595; eLibrary SPIN: 9625-2947; e-mail: i.lipatoff2012@yandex.ru

Тезиков Юрий Владимирович, д.м.н., профессор [Yuri V. Tezikov, MD, PhD, Professor];

ORCID: https://orcid.org/0000-0002-8946-501X; Researcher ID: C-6187-2018; eLibrary SPIN: 2896-6986; e-mail: yra.75@inbox.ru

Азаматов Амир Русланович [Amir R. Azamatov, MD]; ORCID: http://orcid.org/0000-0003-0372-6889;

Scopus Author ID: 57208693102; eLibrary SPIN: 9261-9264; e-mail: azamatov.amir@yandex.ru

*Автор, ответственный за переписку / Corresponding author.

\section{ЦИТИРОВАТЬ:}

Липатов И.С., Тезиков Ю.В., Азаматов А.Р. Дисметаболические механизмы развития преэклампсии // Ожирение и метаболизм. - 2020. - Т. 17. — №4. - С. 346-356. doi: https://doi.org/10.14341/omet12330

\section{TO CITE THIS ARTICLE:}

Lipatov IS, Tezikov YV, Azamatov AR. Dysmetabolic mechanisms of preeclampsia development. Obesity and metabolism. 2020;17(4):346-356. doi: https://doi.org/10.14341/omet12330 